\title{
Premature valve closure in patients with a mitral Starr-Edwards prosthesis and aortic incompetence
}

\author{
T. M. Agnew and R. Carlisle ${ }^{1}$ \\ From the Cardiology Department, Green Lane Hospital, Auckland 3, New Zealand
}

\begin{abstract}
A mitral Starr-Edwards ball valve has, in three patients with concomitant aortic incompetence, permitted recognition of intermittent premature valve closure by auscultation and this has been documented by phonocardiograms. In two instances the observations were confirmed during cardiac catheterization. The features of premature Starr valve closure are described and the mechanism is discussed.
\end{abstract}

Premature mitral valve closure induced by aortic incompetence and accompanied by reversal of the mitral pressure gradient in late diastole is now a well-recognized phenomenon with features that have been described in a number of reports (Wright, Toscano-Barboza, and Brandenburg, 1956; Welch, Braunwald, and Sarnoff, I957; Dodge, Sandler, and Evans, 1960; Kelly, Morrow, and Braunwald, 1960; Meadows, Sharp, and Zacharioudakis, 1962; Meadows et al., 1963; Rees et al., I964; Wigle and Labrosse, I965; Aldridge, Lansdown, and Wigle, 1966; Lochaya, Igarashi, and Shaffer, 1967; Oliver, Gazetopoulos, and Deuchar, I967; Wong, 1969). This may also occur in patients with a Starr-Edwards mitral prosthesis who later develop significant aortic incompetence. Premature closure of the prosthetic valve can be identified by characteristic auscultatory findings, which are the subject of this report.

\section{Patients and methods}

Three patients were studied in whom aortic regurgitation through a deficient aortic valve homograft was causing intermittent premature closure of a Starr-Edwards mitral valve. Cases I and 2 presented acutely after rupture of an aortic homograft cusp. In both, gross aortic incompetence had been followed by signs of severe congestive heart failure. Case 3 was known to have incompetence from the time of his aortic replacement operation. This was moderately severe in degree, but initially was well tolerated. Symptoms of nocturnal breathlessness later resulted in his referral for reassessment. Received 29 December 1969.

1 Present address: Department of Medicine (Cardiology), University of Ibadan, Ibadan, Nigeria.
He did not show features of severe congestive heart failure.

In all, the auscultatory findings were confirmed by phonocardiography. Cardiac catheterization of the first patient was not performed because of the need for urgent aortic valve replacement. In Cases 2 and 3 catheter studies were undertaken. Transseptal entry to the left atrium was not attempted because both patients were on anticoagulant therapy. However, wedge pulmonary artery pressures and left ventricular pressures, obtained by retrograde entry, were recorded simultaneously with a high frequency external phonocardiogram. Cardiac output measurements were made using the Fick principle, and the studies were concluded following cine-aortography in the right anterioroblique position.

\section{Results}

It was found that premature closure of a mitral Starr-Edwards prosthesis resulted in a separate click that occurred in mid- or late diastole, after which there was absence of the valve closure sound that normally occurs with the onset of ventricular systole (Fig. I). Atrial fibrillation was present in each of the three patients under consideration, and premature closure was readily audible during the longer cycles (Fig. 2). In these circumstances there is no audible closing sound with the onset of the succeeding ventricular contraction, and it will be noted in Fig. 2, where a number of consecutive cardiac cycles was analysed for each patient, that premature closure occurred earlier in Cases $I$ and 2 than in Case 3. In both of the first two cases gross congestive heart failure was present and had resulted in tricuspid incompetence with conspicuous in- 
crease in central venous pressure and hepatic enlargement, but in Case 3 the systemic venous pressure was not raised.

Aortic incompetence was graded as clinically severe in each of the 3 patients. This was confirmed by cine-aortography in Cases 2 and 3, using previously defined criteria (Brandt et al., 1969). In Case 2 the aortogram showed immediate reflux of contrast material, with dense outlining of the left ventricle, the material persisting until the end of a ro-second run. The aortogram in the third patient also showed early outlining of the left ventricle, but in contrast with Case 2 the chamber appeared more capacious, retrograde filling was slightly less rapid, and clearing of radioopaque dye occurred more quickly. Aortic incompetence thus appeared slightly less severe in Case 3. Both showed increased indirect left atrial and left ventricular diastolic pressures (Table). The level of left ventricular diastolic pressure was to some extent dependent upon cycle length, and higher pressures were recorded during the longer diastolic filling periods. In neither case was there mitral incompetence. Both patients had a low cardiac output and a slightly raised pulmonary arteriolar resistance.

\section{Discussion}

Closure of a mitral Starr-Edwards prosthesis normally occurs as a result of rising left ventricular pressure during the onset of systole, and produces a high frequency sound of brief duration, which may be followed by one or two lesser vibrations as the ball seats in the rim of the cage (Hultgren and Hubis, 1965). With ventricular relaxation the aortic valve closes and left ventricular diastolic pressure falls below that of the left atrium to permit opening of the ball valve and diastolic filling of the ventricle. In patients who have severe aortic incompetence and a Starr-Edwards mitral prosthesis, premature valve closure may occur as a result of increasing left ventricular diastolic pressure. Such early valve closure is clearly recognizable by the presence of an extra click occurring in mid or late diastole. In such circumstances the ball has already seated at the time the left ventricle begins to contract; and the usual closing sounds of the Starr valve will be muffled or absent. The importance of a correct interpretation of these findings is stressed, since they may otherwise raise the suspicion of abnormal function of the prosthetic valve due to thrombus formation.

It has been shown that the mitral StarrEdwards prosthesis normally offers some obstruction to forward flow (Judson et al., 1963; Morrow et al., 1967). Recently it has been

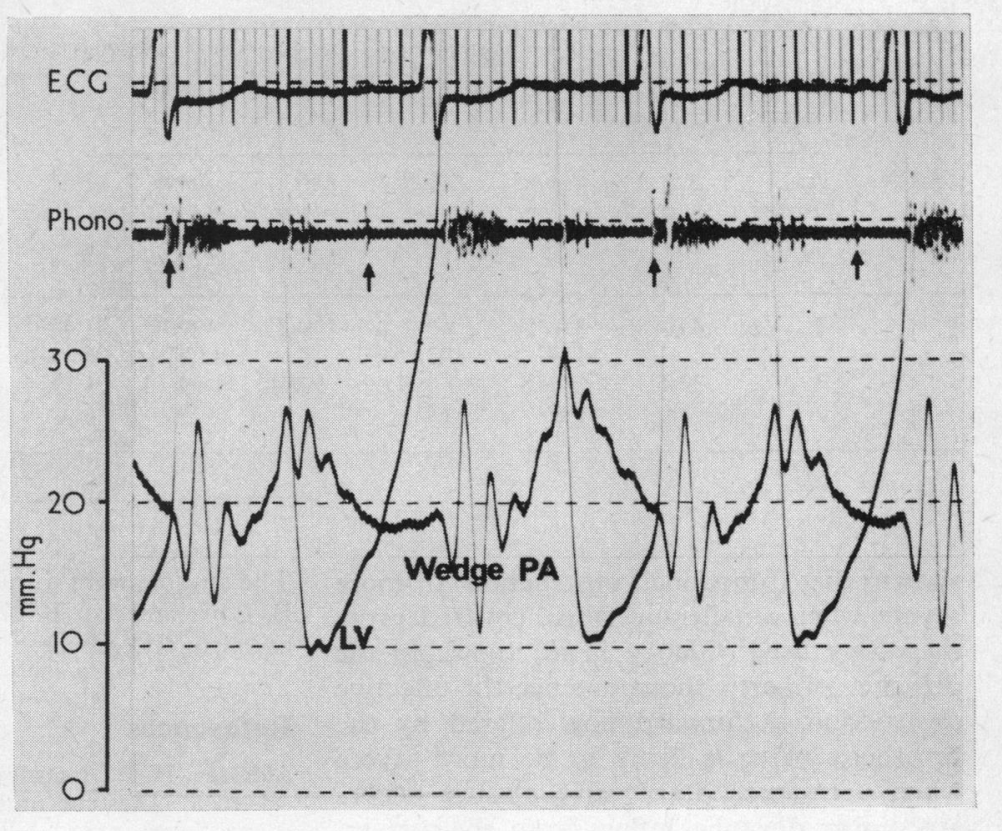

FIG. I Case 2. Simultaneous recordings of wedge pulmonary artery and left ventricular pressures, together with electrocardiogram and high frequency apical phonocardiogram. Starr valve closure indicated by arrows. Premature closure sounds coincide with reversal of mitral gradient.

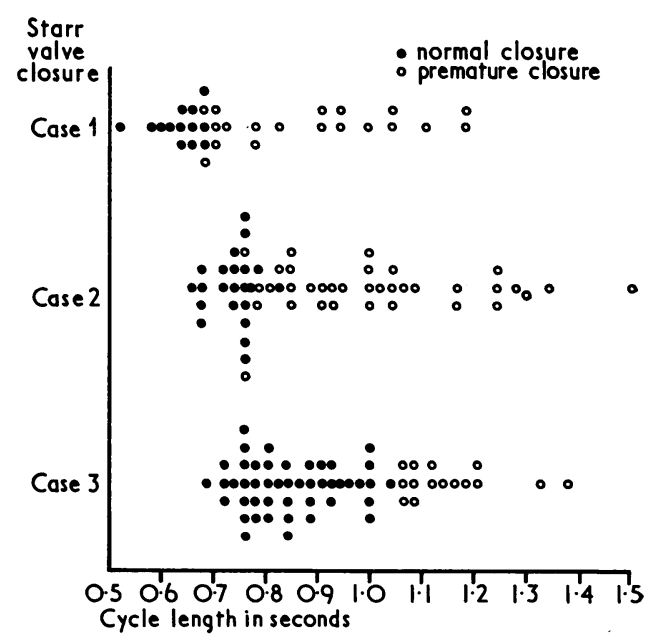

FIG. 2 The timing of Starr valve closure related to the length of the cardiac cycle is shown for each patient. Consecutive cycles were analysed from the phonocardiogram alone in Case $I$ and from phonocardiograms and simultaneous pressure records in Cases 2 and 3. 
TABLE Results of cardiac catheterization

\begin{tabular}{|c|c|c|c|c|c|c|c|c|c|}
\hline \multirow[b]{2}{*}{ Case No. } & \multicolumn{6}{|c|}{ Pressures (mm. Hg) } & \multirow[b]{2}{*}{$\begin{array}{l}\text { Body } \\
\text { surface } \\
\text { area } \\
\left(m .^{2}\right)\end{array}$} & \multirow[b]{2}{*}{$\begin{array}{l}\text { Cardiac } \\
\text { index } \\
\left(l . / \min . / m .^{2}\right)\end{array}$} & \multirow[b]{2}{*}{$\begin{array}{l}\text { Pulm. } \\
\text { arteriolar } \\
\text { resistance } \\
\text { (units) }\end{array}$} \\
\hline & $\begin{array}{l}\text { Rt. } \\
\text { atrium }\end{array}$ & $\begin{array}{l}R t . \\
\text { ventricle }\end{array}$ & $\begin{array}{l}\text { Pulm. } \\
\text { artery }\end{array}$ & $\begin{array}{l}\text { Wedge } \\
\text { pulm. } \\
\text { artery }\end{array}$ & $\begin{array}{l}\text { Left } \\
\text { ventricle }\end{array}$ & Aorta & & & \\
\hline 2 & 7 & $44 / 4$ & $\begin{array}{l}45 / 25 \\
(32)\end{array}$ & $\begin{array}{l}V=7 \\
(23)\end{array}$ & $160 / 35$ & $\begin{array}{l}160 / 64 \\
(100)\end{array}$ & $I \cdot 44$ & $2 \cdot 6$ & $2 \cdot 7$ \\
\hline 3 & 2 & $30 / 5$ & $\begin{array}{l}30 / 15 \\
(20)\end{array}$ & $\begin{array}{l}V=7 \\
(12)\end{array}$ & $90 / 14$ & $\begin{array}{l}90 / 14 \\
(60)\end{array}$ & $\mathrm{I} \cdot 78$ & $1 \cdot 85$ & $2 \cdot 4$ \\
\hline
\end{tabular}

shown that functional obstruction is more severe when smaller or fabric covered prostheses are used (Glancy et al., 1969). In the presence of aortic incompetence the effective obstruction to forward flow offered by the prosthetic valve is likely to be more severe when premature Starr valve closure occurs and limits diastolic inflow from the atrium. This will, in part, be compensated by an increase in left atrial pressure in the cycle after premature closure, with a resultant more rapid early diastolic inflow. The over-all effect is, however, likely to lead to an abnormally high left atrial mean pressure with secondary effects on the pulmonary circulation.

It was noted that left ventricular enddiastolic pressures were raised in both of the patients who were catheterized. The two major factors that affect the left ventricular filling pressure are the capacity of the ventricle and the rate of ventricular filling. The former is dependent upon left ventricular cavity size and also its compliance, while the latter is a function of both forward flow from left atrium and retrograde flow from the aorta when aortic incompetence is present. Volumetric methods and indicator dilution techniques have both been used to quantitate regurgitant flow in patients with aortic incompetence (Jones et al., 1964; Frank et al., 1966). These authors have shown that when the lesion is severe regurgitant flow may be considerably in excess of the effective forward flow. It is likely, therefore, that in patients with severe aortic regurgitation and heart failure the major determinant of left ventricular end-diastolic pressure is the volume of retrograde blood flow, which is itself dependent upon the length of the diastolic filling period. It is not, therefore, surprising that premature closure consequent upon a reversal of the normal atrioventricular diastolic gradient was closely related in each patient to the length of the cardiac cycle.
The authors wish to record their thanks to Dr. J. B. Lowe and Mr. B. G. Barratt-Boyes for helpful criticism and advice.

\section{References}

Aldridge, H. E., Lansdown, E. L., and Wigle, E. D. (1966). Diastolic mitral insufficiency. Circulation, 34, Suppl. 3, 42.

Brandt, P. W. T., Roche, A. H. G., Barratt-Boyes, B. G., and Lowe, J. B. (1969). Radiology of homograft aortic valves. Thorax, 24, 129.

Dodge, H. T., Sandler, H., and Evans, T. (1960). Observations on the hemodynamics of severe aortic insufficiency in man. Circulation, 22, 741.

Frank, M. J., Casanegra, P., Nadimi, M., Migliori, A. J., and Levinson, G. E. (1966). Measurement of aortic regurgitation by upstream sampling with continuous infusion of indicator. Circulation, 33, 545.

Glancy, D. L., O'Brien, K. P., Reis, R. L., Epstein, S. E., and Morrow, A. G. (1969). Hemodynamic studies in patients with $2 M$ and $3 M$ Starr-Edwards prostheses: Evidence of obstruction to left atrial emptying. Circulation, 39, Suppl. I, II3.

Hultgren, H. N., and Hubis, H. (I965). A phonocardiographic study of patients with the StarrEdwards mitral valve prosthesis. American Heart Fournal, 69, 306.

Jones, J. W., Rackley, C. E., Bruce, R. A., Dodge, H. T., Cobb, L. A., and Sandler, H. (I964). Left ventricular volumes in valvular heart disease. Circulation, 29, 887.

Judson, W. E., Ardaiz, J., Strach, T. B. J., and Jennings, R. S. (1963). Postoperative evaluation of prosthetic replacement of aortic and mitral valves. Circulation, 28, 744.

Kelly, E. R., Morrow, A. G., and Braunwald, E. (I960). Catheterization of the left side of the heart. $A$ key to the solution of some perplexing problems in cardiovascular diagnosis and management. New England Fournal of Medicine, 262, 162.

Lochaya, S., Igarashi, M., and Shaffer, A. B. (1967). Late diastolic mitral regurgitation secondary to aortic regurgitation: Its relationship to the Austin Flint murmur. American Heart fournal, 74, 16r.

Meadows, W. R., Sharp, J. T., and Zacharioudakis, S. (1962). Hemodynamic explanation for absence of the first sound in aortic insufficiency. Circulation, 26, 76r.

, Van Praagh, S., Indreika, M., and Sharp, J. T. (1963). Premature mitral valve closure. A hemodynamic explanation for absence of the first sound in aortic insufficiency. Circulation, 28, $25 \mathrm{I}$. 
Morrow, A. G., Oldham, H. N., Elkins, R. C., and Braunwald, E. (1967). Prosthetic replacement of the mitral valve: Preoperative and postoperative clinical and hemodynamic assessments in 100 patients. Circulation, 35, 962.

Oliver, G. C., Jr., Gazetopoulos, N., and Deuchar, D. C. (1967). Reversed mitral diastolic gradient in aortic incompetence. British Heart fournal, 29, 239.

Rees, J. R., Epstein, E. J., Criley, J. M., and Ross, R. S. (1964). Haemodynamic effects of severe aortic regurgitation. British Heart fournal, 26, 4I2.

Welch, G. H., Braunwald, E., and Sarnoff, S. J. (1957).
Hemodynamic effects of quantitatively varied experimental aortic regurgitation. Circulation $R e-$ search, $5,546$.

Wigle, E. D., and Labrosse, C. J. (1965). Sudden, severe aortic insufficiency. Circulation, 32, 708.

Wong, M. (1969). Diastolic mitral regurgitation. Haemodynamic and angiographic correlation. British Heart fournal, 31, 468.

Wright, J. L., Toscano-Barboza, E., and Brandenburg, R. O. (1956). Left ventricular and aortic pressure pulses in aortic valvular disease. Proceedings of the Staff Meetings of the Mayo Clinic, 31, 120. 